\title{
Musculoskeletal biomechanics in sit-to-stand and stand-to-sit activities with stroke subjects: a systematic review
}

\section{Biomecânica musculoesquelética em atividades de levantar/sentar na cadeira em hemiparéticos: revisão sistemática}

\author{
Christina Danielli Coelho de Morais Faria ${ }^{[a]}$, Viviane Amaral Saliba ${ }^{[b]}$, \\ Luci Fuscaldi Teixeira-Salmela ${ }^{[c]}$
}

[a] Fisioterapeuta, Mestre em Ciências da Reabilitação, Departamento de Fisioterapia, Universidade Federal de Minas Gerais (UFMG), Belo Horizonte, MG - Brasil, e-mail: cdcmf@ufmg.br

b] Fisioterapeuta, Especialista em Fisioterapia em Neurologia, Departamento de Fisioterapia, Universidade Federal de Minas Gerais (UFMG), Belo Horizonte, MG - Brasil, e-mail: vivisaliba@yahoo.com.br

[c] Fisioterapeuta, Doutora, Departamento de Fisioterapia, Universidade Federal de Minas Gerais (UFMG), Belo Horizonte, MG - Brasil, e-mail:1fts@ufmg.br

\begin{abstract}
Introduction: Sit-to-stand and stand-to-sit are two of the most mechanically demanding activities undertaken in daily life and which are usually impaired in stroke subjects. Objectives: To determine the distinguishing characteristics in musculoskeletal biomechanical outcomes of the sit-to-stand and stand-to-sit activities with stroke subjects, with an emphasis on the clinical management of stroke disabilities, in a systematic review. Material and methods: An extensive literature search was performed with the MEDLINE, CINAHL, EMBASE, PEDro, LILACS, and SciELO databases, followed by a manual search, to select studies on musculoskeletal biomechanical outcomes in both activities with stroke subjects, without language restrictions, and published until December/2007. Results: Out of the 432 studies, only 11 reported biomechanical outcomes of both activities and none reached the total score on the selected quality parameters. The majority of the experimental studies which compared groups did not achieve acceptable scores on their methodological quality (PEDRo). The investigated conditions and interventions were also restricted. Only one study compared biomechanical outcomes between the activities, but only evaluated the time spent to perform them. Few musculoskeletal biomechanical outcomes have been investigated, being weight bearing on the lower limbs and duration of the activities the most investigated. Conclusion: There is little information regarding musculoskeletal biomechanical outcomes during these activities with stroke subjects and no definite conclusions can be drawn regarding the particularities of these outcomes on their performance with stroke survivors.
\end{abstract}

Keywords: Stroke. Biomechanics. Review. 


\section{Resumo}

Introdução: Levantar/sentar em uma cadeira são atividades de grande demanda mecânica e comumente alteradas em indivíduos hemiparéticos. Objetivos: Determinar as características que distinguem os desfechos relacionados à biomecânica musculoesquelética durante as atividades de levantar/sentar em uma cadeira, enfatizando a abordagem clínica de hemiparéticos com incapacidades, a partir de uma revisão sistemática da literatura científica. Metodologia: Uma ampla busca na literatura foi realizada nas bases de dados MEDLINE, CINAHL, EMBASE, PEDro, LILACS e SciELO, seguida por busca manual para selecionar estudos que reportaram a biomecânica musculoesquelética durante ambas as atividades de levantar/sentar em uma cadeira, em indivíduos hemiparéticos, sem restrição quanto ao idioma e publicados até dezembro/2007. Resultados: Dos 432 estudos encontrados, apenas 11 reportaram dados relacionados com a biomecânica musculoesquelética durante ambas as atividades, os quais não atingiram a pontuação total dos parâmetros de qualidade. Além disso, a maioria dos estudos experimentais que compararam grupos diferentes não atingiu pontuações aceitáveis de qualidade metodológica (PEDro). Apenas um estudo comparou variáveis biomecânicas entre ambas as atividades, mas avaliaram apenas o tempo para desempenhá-las. Poucas variáveis biomecânicas foram investigadas, sendo a descarga de peso nos membros inferiores e a duração das atividades as mais reportadas. Conclusão: Há pouca informação a respeito da biomecânica musculoesquelética durante ambas as atividades de levantar/sentar em uma cadeira em hemiparéticos, portanto, nenhuma conclusão a respeito das características que distinguem cada atividade desempenhada por hemiparéticos pode ser obtida com os dados já publicados.

Palavras-chave: Acidente cerebral vascular. Biomecânica. Revisão.

\section{Introduction}

Standing from seated position and sitting from a standing position (1-4) are two of the most common daily activities. The ability to effectively perform the sit-to-stand and stand-to-sit activities (35 ) are important pre- and post-requisites for upright mobility $(5,6)$ and, therefore, for the performance of other common daily activities. Thus, these functional activities are fundamental components for the independence of persons with disabilities (2, 6-8). Therefore, the acquired knowledge from these analyses is essential to rehabilitation.

Stroke has an important impact on all components of functionality $(9,10)$ and is considered one of the most common causes worldwide of long-term disability $(9,11)$. Over the past two decades, studies have been published regarding the performance of stroke subjects on the sit-to-stand and, to a lesser extent, on stand-to-sit activities (12) and they commonly reported outcomes that are related to musculoskeletal biomechanics. As pointed out by Riley et al. (4), rising from a chair and sitting down are two of the most mechanically demanding activities occurring in daily. Therefore, the quantification of the biomechanical outcomes associated with the ability to stand from a chair and to sit down important to address the control strategies that may impact the successful completion of these tasks with stroke subjects (8).

Janssen, Bussmann and Stam (2), in a review on the determinants of the sit-to-stand task, pointed out that previous review studies on this task were not recent. Specifically, for stroke subjects, there were not found any reviews on the musculoskeletal biomechanics during the performance of both the sit-to-stand and stand-to-sit activities. Considering the importance of these variables to plan future studies and to guide clinical practice in rehabilitation, the general purpose of this review was to determine the distinguishing characteristics in musculoskeletal biomechanical outcomes of both the sit- 
to-stand and stand-to-sit activities with stroke subjects, with an emphasis on the clinical management of stroke disabilities. The specific purposes were: 1 (to point out the particularities of the musculoskeletal biomechanical outcomes related to each activity; 2) to describe the most of the investigated biomechanical outcomes that were significantly modified by different conditions or interventions aimed at improving the performance of these activities; 3) to give direction for future studies regarding musculoskeletal biomechanical outcomes in both the sit-to-stand and stand-to-sit activities with stroke subjects.

\section{Materials and methods}

The present study is a systematic review of observational and experimental research, following recommendations of Vet et al. All steps were conducted by two independent examiners. After each step, consensus was established between the results of both examiners. A third examiner was involved in the process when agreement could not be established between the two examiners.

Firstly, searches were conducted with MEDLINE (OVID), CINAHL (OVID), EMBASE (OVID), PEDRo, LILACS, and SCIELO databases without language restrictions. To select the studies published with stroke subjects, a search strategy elaborated by the Cochrane Collaboration was employed (13), followed by a combination of controlled vocabulary and word text terms related to the activities of interest: "sit to stand", "sit-to-stand", "ris\$”, “standing up", "chair", "stand to sit", "standto-sit", "sit\$", and "sitting down". This previous search strategy was modified to suit the PEDRo, LILACS, and SCIELO databases.

The next steps were related to the selection of the retrieved studies, by considering the following inclusion criteria: articles in all languages; complete and original articles published up to December, 2007; articles reporting objective musculoskeletal biomechanical variables related to stroke performance during both sit-to-stand and stand-to-sit activities. During the second step, the title and the abstract of all papers were read and all which did not reach the inclusion criteria were excluded. In the third step, full paper copies were retrieved, read and the ones that did not reach the inclusion criteria were excluded. During the review of the retrieved papers against the inclusion criteria, reviewers were blinded to the authors and the journal. In the fourth step, a manual search included gleaning references cited in the selected studies was also performed following all of these previous steps.

The fifth step was the allocation of the included papers into groups for future analyses of their results and content. Considering the methodological designs of the studies, they were divided into the following groups (14): 1. Observational research (investigations that did not have control over the studied variables); 2. Experimental research that compared different conditions (investigations in which the researcher manipulated and controlled one or more variables to compare the conditions); 3. Experimental research that compared intervention groups (investigations in which the researcher manipulated and controlled one or more variables in order to compare intervention groups). The sixth step was related to the quality assessment of the included papers. As adopted by previous systematic reviews (15), after extensive discussions between the examiners, 10 general evaluation parameters were defined for the quality assessment. These parameters were selected based upon previous descriptions regarding the determinants of the performance of the sit-to-stand or stand-to-sit activities $(2,7)$ and on the methodological roles that should be followed for reporting the scientific research outcomes (14). Therefore, all included studies received one point for each described parameter. The sum of the scores, which were all equally weighted, was used for the final ranking of the quality of the outcomes. Total scores equal to or close to 10 were associated with high quality. A seventh and last step was carried out for the assessment of the quality of the experimental research that compared the intervention groups. This assessment was carried out using the PEDro scale, which is designed for rating methodological quality of randomized controlled trials. The PEDro scale is an 11-item scale, where 10 items are evaluated and item 1, unlike the other items, is related to external validity and it is not computed in the final score. Ten-point studies are considered to have the highest methodological quality(16). 


\section{Results and discussion}

From the database and manual search, 420 and 12 papers were selected, respectively, for the analyses. From 420 papers from the database, 316 were excluded during the second step, and 95 during the third step, since they did not meet the inclusion criteria. From the 12 papers from the manual search, 10 were also excluded for the same reasons. In total, 11 papers were reviewed, nine from the database search $(12,17-24)$ and two from the manual search $(25,26)$. Despite the large number of identified studies, only a few matched the inclusion criteria. The majority of excluded studies did not provide data related to musculoskeletal biomechanical outcomes in both the sit-to-stand and stand-to-sit tasks with stroke. In spite of the increased number of studies that have been published over the last two decades regarding the performance of stroke subjects during those activities (12), the majority investigated only the sit-to-stand task and have been mainly conducted with healthy subjects (27).

Another important finding of this review was that no studies compared the biomechanical outcomes between the sit-to-stand and stand-to-sit activities. Of the 11 studies included in the present systematic review, only one compared between the sit-to-stand and stand-to-sit, the time spent to complete the tasks (12). The absence of comparisons made it difficult to establish conclusions regarding the distinguishing characteristics of the biomechanical outcomes for each activity performed by stroke subjects, one of the aims of the present study.

Provided that all selected parameters for the assessment of the quality of the studies, the maximum score would have been 10 . However, none of the included studies achieved a score of 10 and the highest score was nine. The majority of the studies showed a quality score of more than $6 / 10$ and only one study had a score lower than 5/10. The outcome variable that was least described was trunk positioning, followed by the speed of the movement (Table 1). All parameters selected for the quality assessment were related to the identified determinants of the performance of the sit-to-stand or stand-to-sit activities $(2,7)$ or to various methodological roles which must be followed on the reporting of outcomes in scientific research (14). The absence of descriptions of one or more of these parameters indicated that the results should be interpreted with caution or that the conclusions wee limited. Furthermore, only the descriptions of the selected parameters would allow the comparisons of the results between studies which compared the same outcome. The absence of this information limited these kinds of comparison in the present review. In a recent study, Galli et al. (27) concluded that the main features of previous studies of the sit-to-stand task showed analyses conducted using different techniques and marker configurations, where subjects were allowed to perform the activity under various or uncontrolled conditions. Therefore, the essential functions of the sit-to-stand task have not been standardized and uniformly defined (27). The same conclusions can be drawn from this present review. Consequently, it is strongly recommended that future studies which report the musculoskeletal biomechanical outcomes

during sit-to-stand and stand-to-sit tasks with stroke subjects include, at least, the description of the selected parameters for the assessment of quality of the studies. 
Table 1 - Assessment of the quality of the included studies ( $\mathrm{n}=11)$

\begin{tabular}{|c|c|c|c|c|c|c|c|c|c|c|c|}
\hline Study & P1 & $\mathbf{P} 2$ & P3 & P4 & P5 & P6 & P7 & P8 & P9 & $\mathbf{P} 10$ & Total \\
\hline Yoshida et al. (1983) & 1 & 0 & 1 & 0 & 0 & 0 & 0 & 1 & 1 & 0 & 4 \\
\hline Engardt and Olsson (1992) & 1 & 1 & 0 & 1 & 1 & 1 & 1 & 1 & 1 & 0 & 8 \\
\hline Engardt et al. (1993) & 1 & 1 & 0 & 0 & 0 & 1 & 1 & 1 & 1 & 0 & 6 \\
\hline Engardt (1994) & 1 & 1 & 1 & 1 & 1 & 1 & 1 & 1 & 1 & 0 & 9 \\
\hline Engardt et al. (1995) & 1 & 1 & 0 & 1 & 1 & 1 & 1 & 1 & 1 & 0 & 8 \\
\hline Cheng et al. (1998) & 1 & 1 & 1 & 1 & 0 & 1 & 0 & 1 & 0 & 1 & 7 \\
\hline Cheng et al. (2001) & 1 & 1 & 1 & 0 & 0 & 1 & 0 & 1 & 0 & 1 & 6 \\
\hline Malouin et al. (2004) & 1 & 1 & 1 & 1 & 1 & 1 & 0 & 1 & 1 & 0 & 8 \\
\hline Howe et al. (2005) & 1 & 1 & 1 & 1 & 0 & 1 & 0 & 0 & 1 & 1 & 7 \\
\hline Roy et al. (2006) & 1 & 1 & 1 & 1 & 1 & 1 & 0 & 1 & 1 & 1 & 9 \\
\hline Roy et al. (2007) & 1 & 1 & 1 & 1 & 1 & 1 & 0 & 1 & 1 & 1 & 9 \\
\hline
\end{tabular}

$\mathrm{P}=$ parameter; $\mathrm{P} 1=$ subjects' age; $\mathrm{P} 2=$ time since onset of stroke; $\mathrm{P} 3=$ both score and variability measures of the musculoskeletal biomechanical outcomes; P4= beginning and end of the sit-to-stand; P5= beginning and end of the stand-to-sit; P6= height of the chair seat; P7 = trunk position; $\mathrm{P} 8=$ foot position; $\mathrm{P} 9=$ upper limb position; $\mathrm{P} 10=$ speed characteristics of the movement

\section{Allocation into groups and analyses of the content and results of the studies}

Of the 11 selected studies, two were classified as observational (Table 2), four as experimental which compared different conditions (Table 3), and five as experimental research which compared intervention groups (Table 4).

Table 2 - Description of observational research on sit-to-stand and stand-to-sit tasks with stroke subjects $(\mathrm{n}=2)$

\begin{tabular}{|c|c|c|}
\hline Study & Subject Characteristics & Measurement Method \\
\hline $\begin{array}{l}\text { Yoshida et al. } \\
\text { (1983) }\end{array}$ & $\begin{array}{l}10 \text { hemiparetics, mean age of } 60.7 \mathrm{y} ; 10 \text { young } \\
\text { males, mean age of } 27.9 \mathrm{y} ; 10 \text { young females, } \\
\text { mean age of } 24.3 \mathrm{y} ; 10 \text { elderly males, mean age } \\
\text { of } 67.4 \mathrm{y} ; 10 \text { elderly females, mean age of } 60 \mathrm{y} \text {. }\end{array}$ & $\begin{array}{l}\text { - Barefoot; back rest and arm rest chair adjusted according } \\
\text { to the length of the subject's leg, ankle at } 0^{\circ} \text { and knee } \\
\text { flexed at } 90^{\circ} \text {, instructed not to use the arms. First, the } \\
\text { sit-to-stand, and after } 30 \mathrm{~s} \text {, the stand-to-sit task. } \\
\text { - Equipment: one force platform (Kyowa Dengyo) under } \\
\text { the paretic foot of hemiparetic subjects or under the right } \\
\text { foot of healthy subjects, and an electrogoniometer with } \\
\text { telemeter. }\end{array}$ \\
\hline $\begin{array}{l}\text { Cheng et al. } \\
\text { (1998) }\end{array}$ & $\begin{array}{l}33 \text { hemiparetics, mean time since stroke of } \\
1.7 \mathrm{~m}, 18 \text { with history of falls, mean age of } \\
62.8 \pm 6.4 \text { y and } 15 \text { without history of falls, } \\
\text { mean age of } 63 \pm 6 y ; 25 \text { age-matched healthy }\end{array}$ & $\begin{array}{l}\text {-Barefoot; armless, backless chair adjusted to the height of } \\
\text { the subject's knee; feet parallel, } 10-15 \mathrm{~cm} \text { apart, ankle } \\
\text { at approximately } 10 \text { degrees of dorsiflexion and knee } \\
\text { at } 100-105 \text { degrees of flexion. Movement at self-paced } \\
\text { speed. First the sit-to-stand, and after } 30 \mathrm{~s} \text {, the stand-to- } \\
\text { sit task. } \\
\text {-Equipment: two force platforms (AMTI) under each foot }\end{array}$ \\
\hline
\end{tabular}

y: years; m: months; BW: body weight 


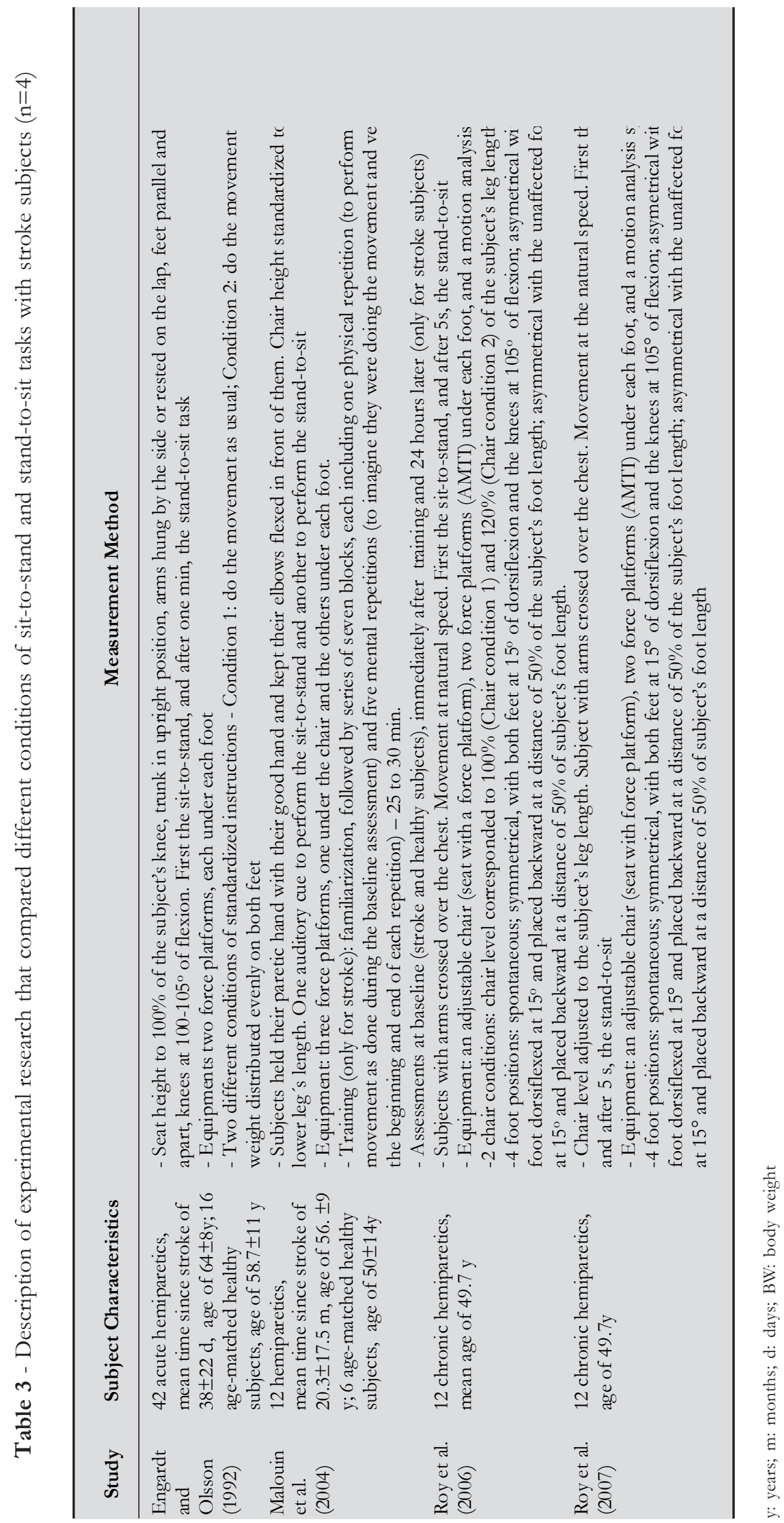




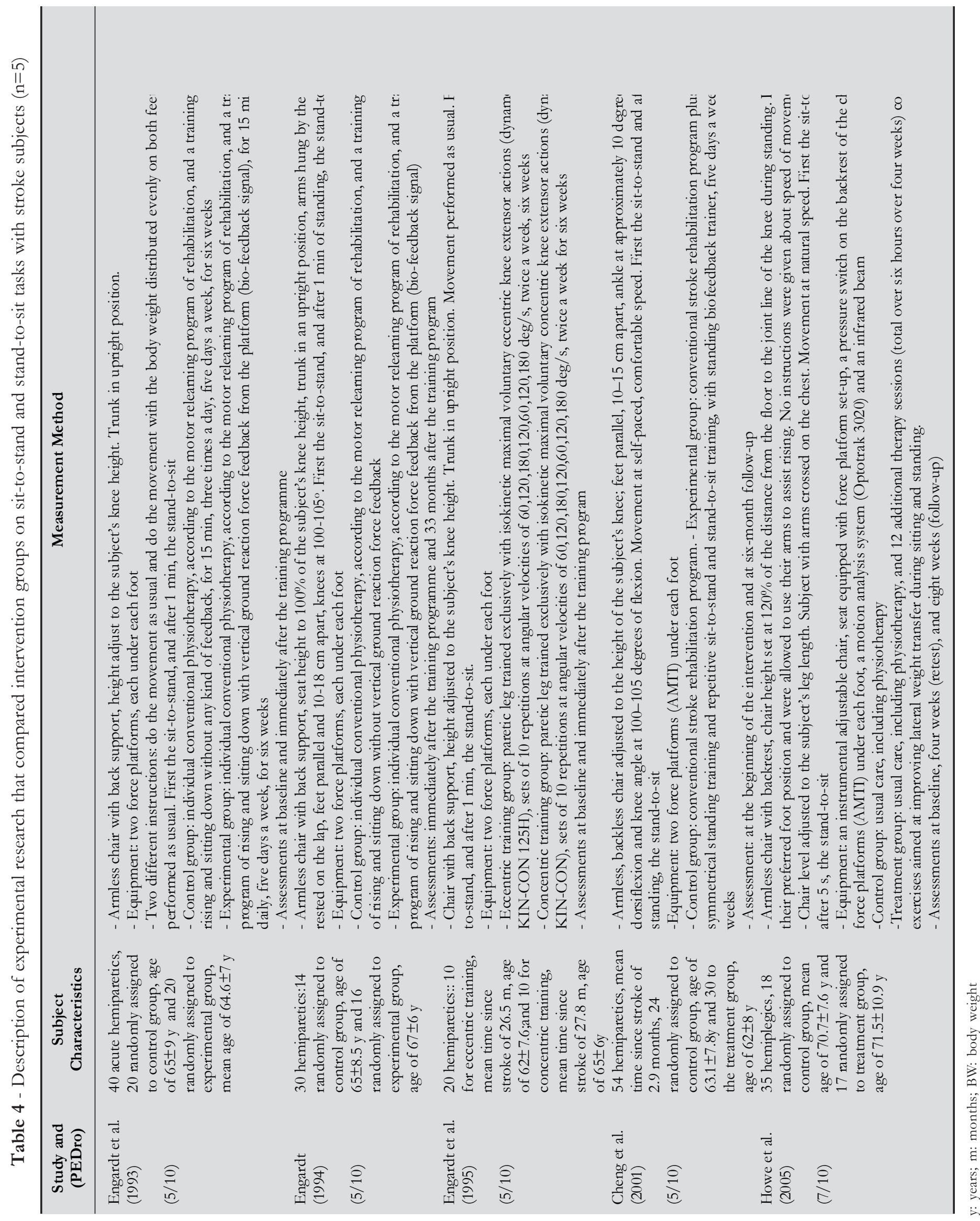


The experimental research which compared different conditions, investigated the effects of the instructions given to the subjects in one study, the effects of the chair height in one study, and the effects of foot positioning on the performance of both sit-to-stand and stand-to-sit tasks in two studies (Table 5). One study also compared the outcomes related to the sit-to-stand and stand-to-sit activities before and after a single session of physical and mental practice (Table 5). Therefore, the conditions that were investigated were also more limited. Furthermore, no studies were found which compared the effects of the speed of the movements, support of the upper limbs, or of other variables that have a direct impact on the biomechanics of both tasks.

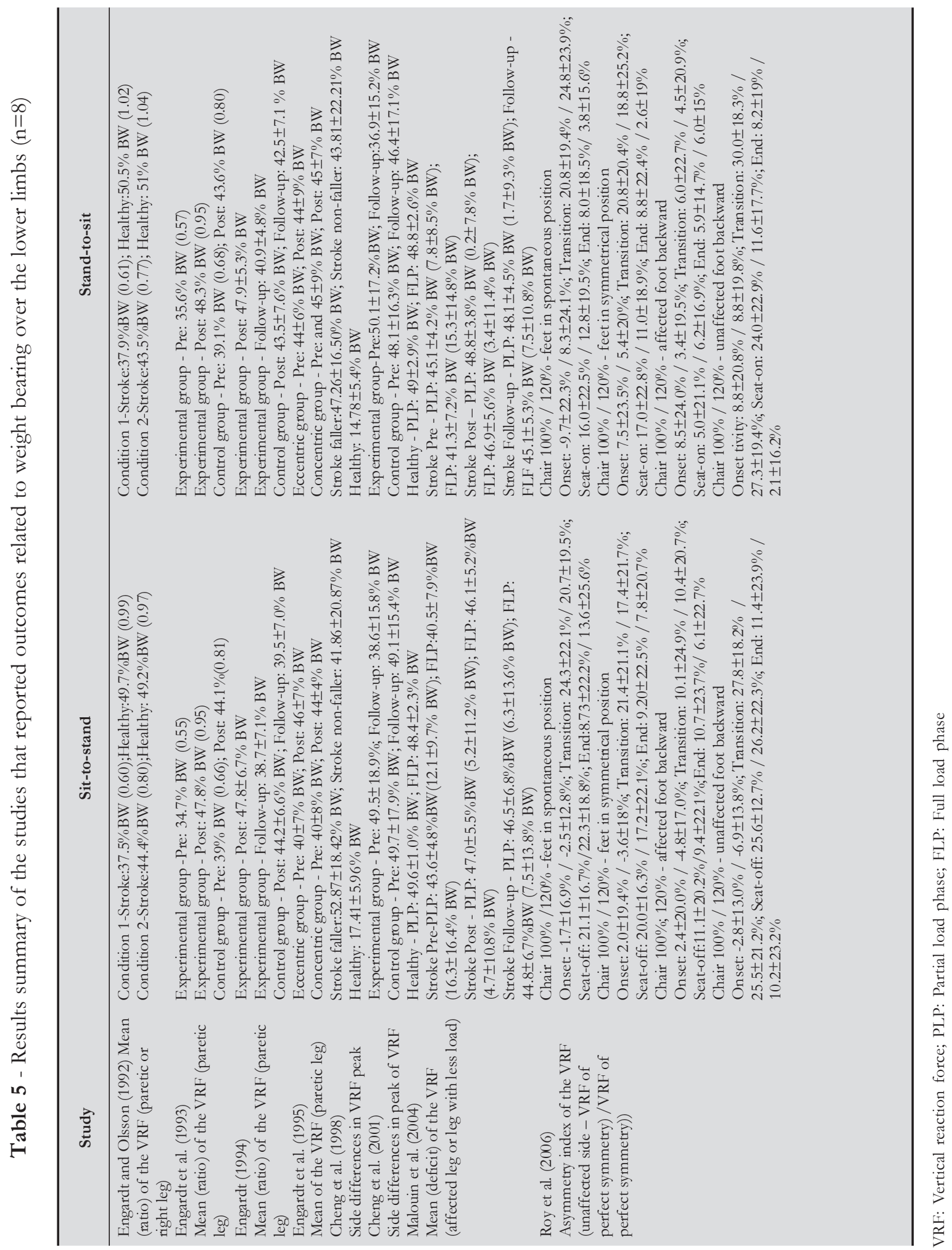


Only one study investigated the effects of the chair height on the biomechanical outcomes of stroke subjects during both the sit-to-stand and stand-to-sit tasks, and no differences were found for any investigated outcomes between different chair heights. Previous studies have reported that mechanical parameters vary with the chair height and found that an elevated chair height in the sitto-stand task is less demanding than a lower chair height $(2,28,29)$. They also pointed out that the maximum vertical ground reaction force values in healthy subjects were decreased with the increases in chair height (29). The net extension moments at the knee and hip also decreased with increases in the chair height (28). Probably, the variability of the data of this study (Table 5), may be associated with the variability of the impairments found in this sample, and with its small size, which may have minimized the effects of the chair height for the asymmetry of the vertical reaction forces (12). In addition, the belief that an elevated chair height in the sit-to-stand task is less demanding than at a lower chair height was established for healthy subjects $(2,28,29)$, and did not specify how elevated the chair should be. Probably, a cut-off level may exist to modify the biomechanical demands, which may be specific for the subjects' characteristics.

Two studies $(12,24)$ investigated the immediate effects of foot positioning on the performance of the sit-to-stand and stand-to-sit activities with stroke subjects. Only the backward position of the affected foot resulted in some improvements, but not in all investigated outcomes. Considering that foot positioning is a strategy usually employed in clinical rehabilitation of stroke subjects to improve their performance in these activities, more investigations are necessary to investigate the effects of the foot positioning with stroke subjects.

Different types of intervention programs were investigated in the studies which compared the intervention groups. Three studies investigated the effects of biofeedback on the symmetry of weight bearing in the lower limbs and all of them were evaluated with a score of 5/10 in the PEDro scale. One evaluated the effects of the eccentric and concentric training of the knee extensor muscles of the paretic leg with a score of 5/10 in the PEDro scale, and one the effects of exercise for the improvement of lateral weight transfer during both the sit-to-stand and stand-to-sit tasks with a score of 7/10 in the PEDro scale (21) (Table 4). In general, the majority of these experimental studies did not reach acceptable scores of their methodological quality, which limited the conclusions that could be drawn regarding the effectiveness of the applied interventions.

One important point that needs to be discussed is that despite the positive effects of progressive resistance strength training following stroke in reducing musculoskeletal impairments (30) and in providing important improvements in the performance of functional activities, such as gait $(31,32)$, only one study investigated the effects of this kind of intervention on the biomechanical outcomes in the sit-to-stand and stand-to-sit tasks with stroke subjects (Table 4). However, no definitive conclusions could be drawn due to the limitations associated with the applied training program, where only the knee muscles of the paretic leg were trained. The methodological limitations of the study were also due to the fact that a single study cannot provide sufficient information to draw conclusions. Therefore, the effects of progressive resistance strength training following stroke for the performance of the sit-to-stand and stand-to-sit tasks are still unclear and should be investigated in future studies.

Finally, it is important to point out the characteristics of the sample that were included in these studies. All subjects had motor impairments, such as hemiparesis/hemiplegia, due to stroke (Tables 2, 3 and 4). Among all of the common disabilities of the stroke survivors, motor disabilities are the most prevalent and disabling, with hemiparesis being the primary target for rehabilitation (33). 
In addition, the severity of hemiparesis was shown to be related to the functional capabilities of the stroke subjects (34) and it may be that this disability has an impact on the biomechanical outcomes of the sit-to-stand and stand-to-sit tasks.

From the studies that reported the time since the onset of stroke, the majority included acute/sub-acute stroke survivors (Tables 3, 4, and 5) and only three studies reported biomechanical outcomes with only chronic stroke survivors. It is well recognized that stroke is the most common cause of long-term disability worldwide and is considered one of the 12 health conditions with the highest burden of disease (9). Thus, it is also important to investigate the biomechanical outcomes of the sit-to-stand and stand-to-sit tasks with chronic stroke survivors for the better understanding of persistent disabilities.

Four studies compared stroke with healthy subjects and only one compared sub-groups of stroke subjects, such as fallers and non-fallers. Therefore, the stroke groups that were compared were also limited. No comparisons were made which considered the sub-groups of stroke subjects with different levels of impairments despite the fact that these subjects show different levels of functioning and potential for functional improvements $(9,35)$. In addition, due to the fact that more than one third of the falls in stroke subjects occur during the sit-to-stand or stand-to-sit tasks (17), it is necessary to carry out more studies to investigate the biomechanical outcomes that could be associated with falls during the rising from a chair and sitting down.

The most investigated biomechanical outcomes during both activities were related to weight bearing on the lower limbs, which were described in eight studies (Table 5), followed by the task duration, described in seven studies (Table 6). Three studies reported outcomes related to mediolateral and anteroposterior sways (Table 7), one was related to kinetic data other than weight bearing (Table 8), and one was related to joint kinematics (Table 8). 


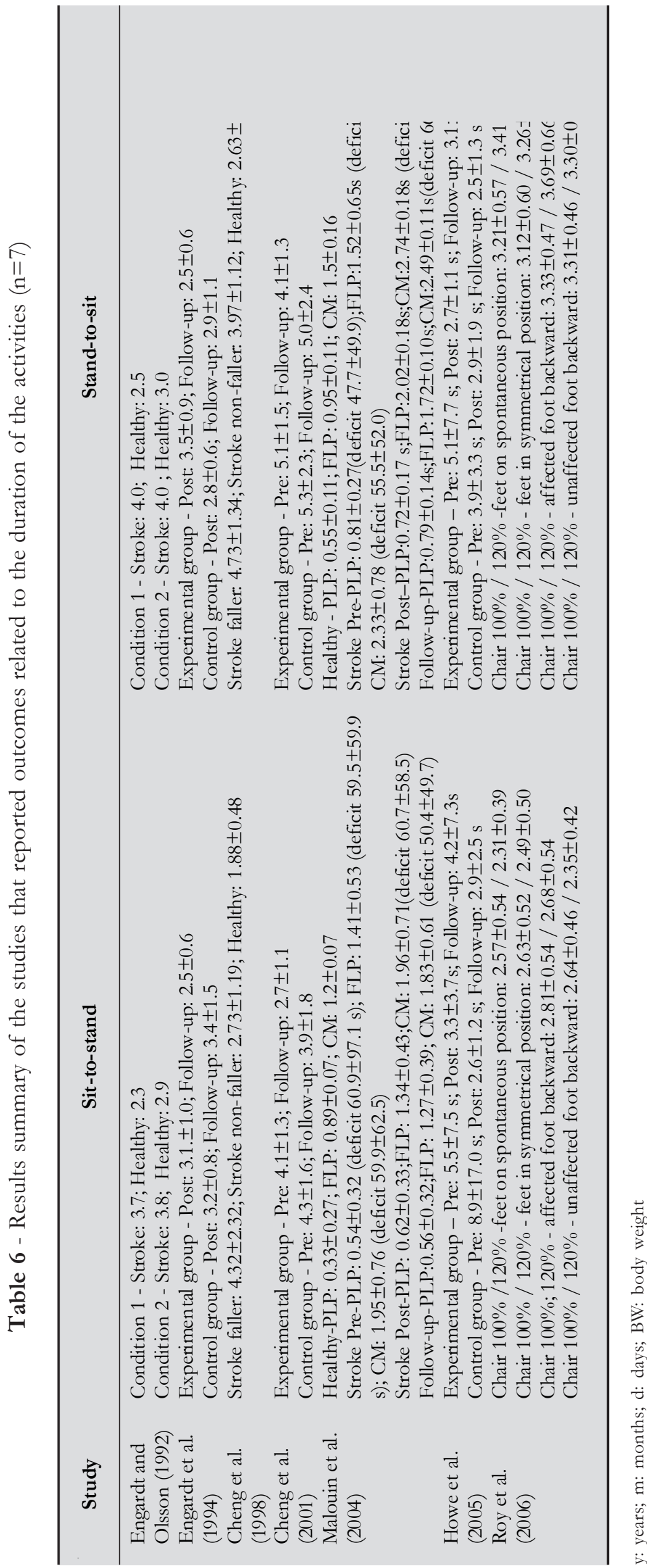




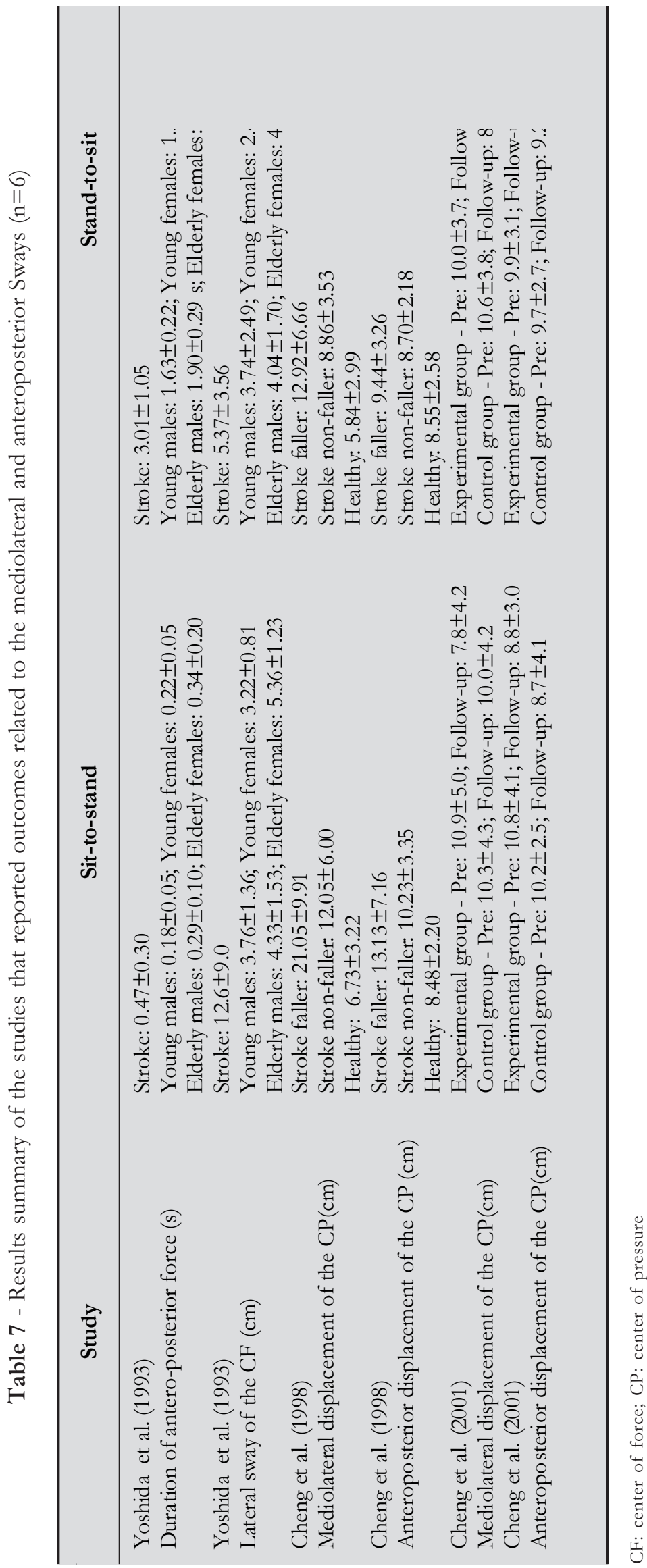




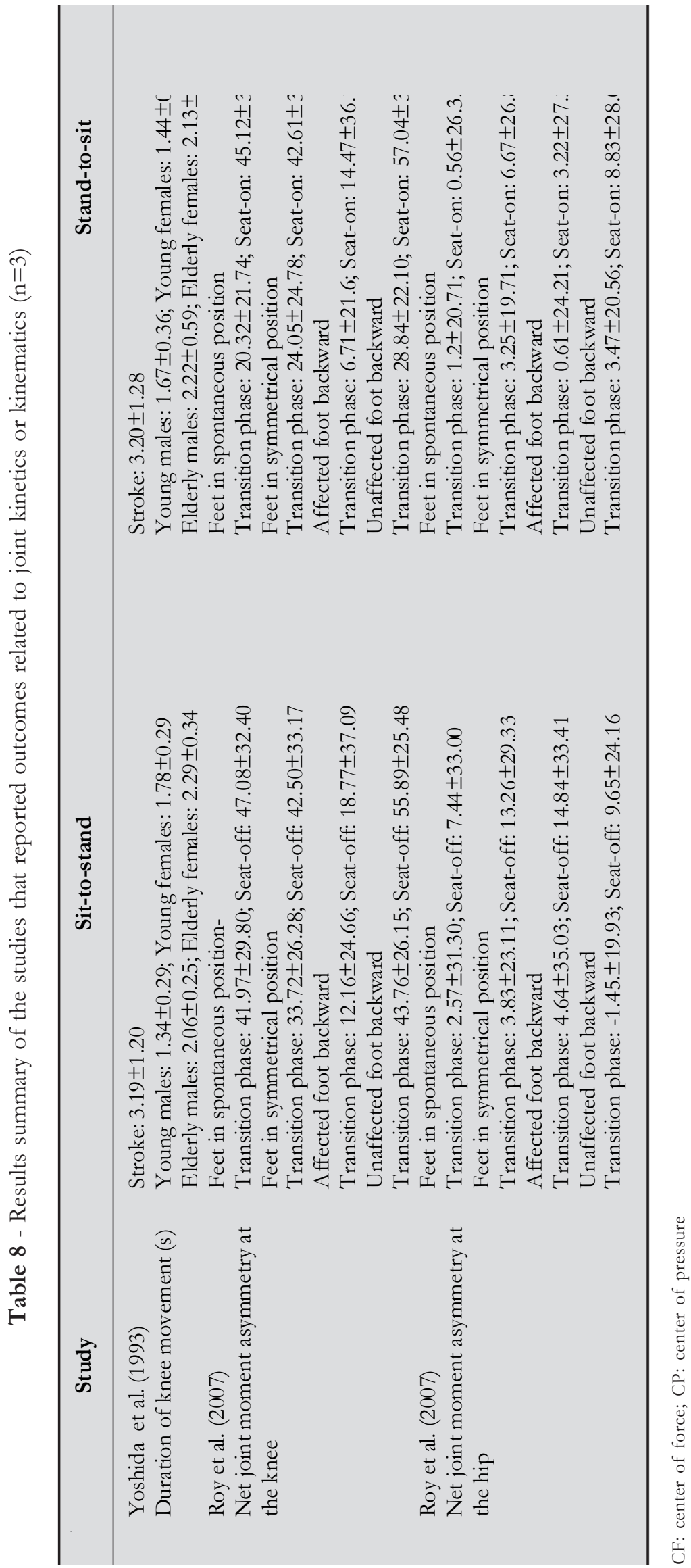




\section{Outcomes related to weight bearing on the lower limbs}

Table 5 provides the numerical values related to weight bearing on the lower limbs in both the sit-to-stand and stand-to-sit activities published in the original articles included in this review. Considering the differences in reported weight bearing parameters and the particularities in the data collection, e.g., the sample characteristics and adopted procedures, it was not possible to compare these results.

In general, it was possible to affirm that during the performance of the sit-to-stand and standto-sit activities, stroke subjects demonstrated asymmetrical weight bearing, when compared to healthy subjects $(17,25)$, but the weight-bearing of the stroke fallers was not different from the non-fallers (17). The instructions to perform both activities with better symmetrical weight bearing appeared to have an immediate positive effect on the symmetry of weight bearing (25). Furthermore, when this type of instruction was associated with conventional care for stroke subjects, the improvements related to symmetry were greater $(18,19)$. However, these improvements were not completely retained over a long time $(18,20)$. The mental practice associated with physical repetitions of the movements also showed positive effects on weight bearing symmetry for both the sit-to-stand and stand-to-sit tasks, with the retention of the improvements 24 hours later. However, it was not possible to affirm that these improvements were due to the mental practice, since these studies did not include a control group (22).

No significant effects were found regarding the chair height conditions (100 or 120\% of the subjects' leg length) on the weight bearing symmetry of the lower-limbs. However, the positioning of the affected foot backwards promoted greater loading on the affected side for both tasks (Table 5).

The weight bearing on the lower limbs was the most investigated biomechanical outcome for both the sit-to-stand and stand-to-sit activities for stroke subjects. During rehabilitation, measures of weight bearing in different situations (e.g., standing) or during the performance of different functional activities (e.g., gait, sit-to-stand, stand-to-sit) are usually described, especially for subjects with neurological impairments, such as stroke. Among all the applied techniques to measure weigh bearing, force platforms are considered the gold standard. Force platforms have a high methodological quality to measure ground reaction forces, provide highly accurate and precise measures, and are considered one of the most important measurement biomechanical devices (36). All eight studies included in the present systematic review that reported weight-bearing employed force platforms. Therefore, the measures provided by these studies were considered of a high methodological quality.

However, it is important to discuss the relevance of the weight bearing symmetry on the

functional performance of stroke subjects. From the eight studies which investigated weight bearing symmetry, only one described measures of functional outcomes, such as performance of daily living activities using the Barthel index. In this study, the group that had the greatest improvements in weight bearing symmetry in the sit-to-stand and stand-to-sit tasks did not show the same improvements in the performance of the daily living activities, when compared to the other group. Both groups showed similar improvements in their performance of daily living activities (19). Previous studies have also demonstrated that improvements in more symmetric patterns were not associated with improvements in functional performance with stroke subjects. Despite the fact that the symmetry allows better muscular synergism and facilitates normal movement patterns, there was weak evidence that symmetry plays an important role in promoting the functioning of stroke subjects (37-39) and that the rehabilitation programs aimed to improve their symmetry have positive effects on functional outcomes after stroke $(40,41)$.

\section{Outcomes related to the duration of the activity}

Table 6 demonstrates the values related to the results of the duration of the activities for both the sit-to-stand and stand-to-sit tasks published in the articles included in the present review. Considering the different definitions of the beginning and end of each activity, and, in some cases, in the absence of this definition, it was not possible to compare the results. In general, it was possible to affirm that stroke victims spent more time than healthy subjects in the performing of both activities $(17,22,22,25)$ and that 
stroke fallers spent more time in performing the sit-to-stand task than the stroke non-fallers (17). Furthermore, conventional care associated with instruction to perform these activities with better weight bearing symmetry seems to have positive, greater and long-term effects on the reduction of time to perform both tasks $(18,26)$. On the other hand, conventional care associated with exercises aimed to improve lateral weight transfer during sitting and standing (21), as well as mental practice associated with physical repetition of the movements (22) did not improve the time spent to perform both activities.

There were no significant effects regarding the chair height conditions neither for the foot positioning nor for the duration of both activities performed by chronic stroke subjects. For all investigated conditions, the duration of both activities was always longer for the sit-to-stand than for the stand-to-sit task (12). As mentioned above, this was the only reported outcome that was compared between the activities (Table 6).

The time spent to perform a specific activity is a simple and important outcome related to the subjects' functional capabilities. Different tests based upon the duration of specific activities have been applied with stroke subjects and have demonstrated adequate psychometric properties, such as gait speed, stair climbing, or the Timed " $U p$ and Go" test (42), and even the five-repetition sit-to-stand task (43). However, no reference values were established for the time spent by stroke subjects to perform the sit-to-stand and stand-to-sit activities.

\section{Outcomes related to medio-lateral and antero-posterior sways}

Table 7 shows the values related to medio-lateral and antero-posterior sway. In general, stroke had a greater lateral sway than healthy subjects during both the sit-to-stand and stand-to-sit tasks $(17,23)$, and stroke fallers had a greater lateral sway than non-fallers (17). The anterior sway was longer for stroke than for healthy subjects during both activities $(17,23)$ and was larger for stroke fallers than for healthy subjects only for the sit-to-stand(17) (Table 7). Conventional stroke rehabilitation programs associated with instructions to increase weight bearing symmetry during the performance of these activities reduced the medio-lateral displacement of the center of pressure during both tasks and the antero-posterior displacement of the center of pressure only for the sit-to-stand task (18).

Greater medio-lateral sway can be associated with poor dynamic postural stability in performing the activities and can reflect weight bearing symmetry $(17,18)$. Greater antero-posterior sway, associated with a longer time of the anteroposterior force, might be due to excessive momentum during the transfer phase while rising from a chair $(1,17)$. The period of antero-posterior force is related to the ensuing forward acceleration, which caused the anterior leaning of the trunk and knee extension. However, the absence of data regarding angular positions, velocities and acceleration of these joints limited the conclusions that could be drawn.

\section{Outcomes related to joint kinematics and kinetics}

Table 8 provides all of the numerical values of the outcomes related to joint kinetics and kinematics for both the sit-to-stand and stand-to-sit activities. Only one study reported data on joint kinematics and it was related to the periods of knee movements for both the sit-to-stand (from $90^{\circ}$ flexion to the maximum extended position) and stand-to-sit (the reversed movement) (Table 2). For the stroke group, the periods of knee movements were longer than for all the other groups, for both activities (Table 8).

Roy et al. (24) published the first and the only data regarding the joint kinetics during both tasks. The results of the total net joint moment variables were reported in small graphics, which made it difficult to obtain these values. For these variables, the statistical analyses reported in the original article revealed that during both the sit-to-stand and stand-to-sit tasks, the net joint moments at the knee were higher for the unaffected than on the affected side, regardless of the foot conditions, except when the affected foot was placed behind. At the hip, no differences between sides for the hip moment were found 
for both activities. In addition, for both the sit-to-stand and stand-to-sit tasks, for both the transition and seat-off (or seat-on) events, the condition of the affected-foot placed behind showed the lowest values of net joint moment asymmetry between sides for the knee. For the stand-to-sit task, the condition of the unaffected foot placed behind showed a higher level of knee joint asymmetry than in the spontaneous and symmetrical foot conditions. Furthermore, for the sit-to-stand task, the knee joint moment asymmetry was lower at transition than at seat-on, except for the condition when the affected-foot was placed behind. Considering the results of the net joint moment asymmetry at the hip, in both the transition and seat-off, or seat-on events, the values did not change with the foot positioning. In addition, the hip moments were similar between the transition and seat-off (or seat-on) events for all foot positions (Table 8).

\section{Final considerations}

This was the first systematic review to pool data from research regarding musculoskeletal biomechanical outcomes during both the sit-to-stand and stand-to-sit activities performed by stroke subjects. In summary, there was found a considerable lack of information regarding the biomechanical outcomes for both the sit-to-stand and stand-to-sit activities with stroke subjects. Therefore, no definite conclusions could be drawn regarding the distinguishing biomechanical characteristics and the effects of different conditions and interventions on these outcomes with stroke survivors.

Few and limited musculoskeletal biomechanical outcomes have been reported for stroke subjects during both the sit-to-stand and stand-to-sit activities. No data were found on the important musculoskeletal biomechanical outcomes, such as angular positions, joint velocities and accelerations, patterns of muscular activation, and the amounts of electromyographic activities, mechanical energy and power. So far, studies on the musculoskeletal biomechanics during both the sit-to-stand and standto-sit activities performed by stroke subjects have focused on weight bearing symmetry, which does not appear to be a relevant outcome on the functional performance and improvement of these subjects.

In addition, important parameters related to some identified determinants of the performance of the sit-to-stand or stand-to-sit activities or to some methodological roles that should be followed for the reporting of outcomes by scientific research have not been described in the majority of studies, which reported on musculoskeletal biomechanics for both tasks performed by stroke subjects. This does not allow comparisons of these results and limits the conclusions that could be drawn from these results.

This systematic review with transparent classifications and reporting was meant to be a starting point and an inspiration for future studies on the reporting of musculoskeletal biomechanical outcomes during both the sit-to-stand and stand-to-sit tasks of stroke subjects.

\section{Acknowledgments: CAPES / FAPEMIG / CNPq.}

\section{References}

1. Schenkman M, Berger RA, Riley PO, Mann RW, Hodge WA. Whole-body movements during rising to standing from sitting. Phys Ther. 1990;70(10):638-48.

2. Janssen W, Bussmann H, Stam H. Determinants of the sit-to-stand movement. Phys Ther. 2002;82(9):866-79.

3. Chou S, Wong M, Leong W, Hong W, Tang F, Lin T. Postural control during sit-to-stand and gait in stroke patients. Am J Phys Med Rehabil. 2003;82(1):42-7.

4. Riley P, Shcenkman M, Mann R, Hodge W. Mechanics of a constrained chair-rise. J Biomech. 1991;24(1):77-85.

5. Pai Y, Rogers M. Segmental contributions to total body momentum in sit-to-stand. Med Sci Sports Exerc. 1991;23(2):225-30. 
6. Kotake T, Dohi N, Kajiwara T, Sumi N, Koyama Y, Miura T. An analysis of sit-to-stand movement. Arch Phys Med Rehabil. 1993;74(10):1095-9.

7. Carr JH, Ow JEG, Shepherd RB. Some biomechanical characteristics of standing up at three different speeds: Implications for functional training. Phys Theor Pract. 2002;18:47-53.

8. Yu B, Holly-Crichlow N, Brichta P, Reeves GR, Zablotny CM, Nawoczenski DA. The effects of the lower extremity joint motions on the total body motion in sit-to-stand movement. Clin Biomech. 2000;15(6):449-55.

9. Geyh S, Cieza A, Schouten J, Dickson H, Frommelt P, Omar Z, et al. ICF Core Sets for stroke. J Rehabil Med. 2004;(44 Suppl):135-41.

10. Duncan P. Stroke disability. Phys Ther. 1994;74(5):399-407.

11. Murray CJL, Lopez AD. Global mortality, disability, and the contribution of risk factors: Global burden of disease study. Lancet. 1997;349(9063):1436-42.

12. Roy G, Nadeau S, Gravel D, Malouin F, McFadyen BJ, Piotte F. The effect of foot position and chair height on the asymmetry of vertical forces during sit-to-stand and stand-to-sit tasks in individuals with hemiparesis. Clin Biomech. 2006;21(6):585-93.

13. Wu HM, Tang JL, Lin XP, Lau J, Leung PC, Woo J, et al. Acunputore for stroke rehabilitation. Cochrane Database Syst Rev. 2006;3:CD004131.

14. Portney LG, Watkins MP. Foundations of clinical research: applications to practice. $2 \mathrm{a}$ ed. New Jersey: Prentice-Hall; 2000.

15. May S, Littlewood C, Bishop A. Reliability of procedures used in the physical examination of non-specific low back pain: a systematic review. Aust J Physiother. 2006;52(2):91-102.

16. Maher CG, Sherrington C, Herbert RD, Moseley AM, Elkins M. Reliability of the PEDro scale for rating quality of randomized controlled trials. Phys Ther. 2003;83(8):713-21.

17. Cheng P, Liaw M, Wong W, Tang F, Lee M, Lin P. The sit-to-stand movement in stroke patients and its correlation with falling. Arch Phys Med Rehabil. 1998;79(9):1043-6.

18. Cheng PT, Wu S, Liaw M, Wong AMK, Tang F. Symmetrical body-weight distribution training in stroke patients and its effect on fall prevention. Arch Phys Med Rehabil. 2001;82(12):1650-4.

19. Engardt M, Ribbe T, Olsson E. Vertical ground reaction force feedback to enhance stroke patients symmetrical body-weight distribution while rising/sitting down. Scand J Rehabil Med. 1993;25(1):41-8.

20. Engardt M, Knutsson E, Jonsson M, Sternhag M. Dynamic muscle strength training in stroke patients: effects on knee extension torque, electromyographic activity, and motor function. Arch Phys Med Rehabil. 1995;76(5):419-25.

21. Howe TE, Taylor I, Finn P, Jones H. Lateral weigth transference exercises following acute stroke: a preliminary study of clinical effectiveness. Clin Rehabil. 2005;19(1):45-53.

22. Malouin F, Richards CL, Doyon J, Desrosiers J, Belleville S. Training mobility tasks after stroke with combined mental and physical practice: a feasibility study. Neurorehabil Neural Repair. 2004;18(2):66-75.

23. Yoshida K, Iwakura H, Inoue F. Motion analysis in the movements of standing up from and sitting down on a chair. A comparison of normal and hemiparetic subjects and the differences of sex and age among the normals. Scand J Rehabil Med. 1983;15(3):133-40.

24. Roy G, Nadeau S, Gravel D, Piotte F, Malouin F, McFadyen BJ. Side difference in the hip and knee joint moments during sit-to-stand and stand-to-sit tasks in individuals with hemiparesis. Clin Biomech. 2007;22(7):795-804.

25. Engardt M, Olsson E. Body weight-bearing while rising and sitting down in patients with stroke. Scand J Rehabil Med. 1992;24(2):67-74. 
26. Engardt M. Long-term effects of auditory feedback training on relearned symmetrical body weight distribution in stroke patients: a follow-up study. Scand J Rehabil Med. 1994;26(2):65-9.

27. Galli M, Cimolin V, Crivellini M, Campanini I. Quantitative analysis of sit to stand movement: experimental set-up definition and application to healthy and hemiplegic adults. Gait Posture. 2008;28(1):80-5.

28. Schenkman M, Riley PO, Pieper C. Sit to stand from progressively lower seat heights - alterations in angular velocity. Clin Biomech. 1996;11(3):153-158.

29. Kawagoe S, Tajima N, Chosa E. Biomechanical analysis of effects of foot placement with varying chair height on the motion of standing up. J Orthop Sci. 2000;5(2):124-33.

30. Morris LS, Dodd KJ, Morris ME. Outcomes of progressive resistance strength training following stroke: a systematic review. Clin Rehabil. 2004;18(1):27-39.

31. Oullette M, LeBrasseur N, Bean J, Philips E, Stein J, Frontera W, et al. High-intensity resistance training improves muscle strength, self-reported function, and disability in long-term stroke survivors. Stroke. 2004;35(6):1404-9.

32. Teixeira-Salmela L, Nadeau S, McBride I, Olney SJ. Effects of muscle strengthening and physical conditioning training on temporal, kinematic and kinetic variables during gait in chronic stroke survivors. J Rehabil Med. 2001;33(2):53-60.

33. HSTAT. Post-stroke rehabilitation. AHCPR Publication 1995 [cited 2007 Out 26];(95-0062). Available from: http://www.ncbi.nlm.nih.gov/bookshelf/br.fcgi?book=hsarchive\&part=A27305

34. Andrews A, Bohannon R. Distribution of muscle strength impairments following stroke. Clin Rehabil. 2000;14(1):79-87.

35. Hershkovitz A, Gottlieb D, Beloosesky Y, Brill S. Assessing the potential for functional improvement of stroke patients attending a geriatric day hospital. Arch Gerontol Geriatr. 2006;43(2):243-8.

36. Hurkmans HLP, Bussmann JBJ, Benda E, Verhaar JAN, Stam HJ. Techniques for measuring weight bearing during standing and walking. Clin Biomec. 2003;18(7):576-89.

37. Olney SJ, Richards C. Hemiparetic gait following stroke. Part I: characteristics. Gait Posture. 1996;4(2):136-48.

38. Tyson SF. Hemiplegic gait symmetry and walking aids. Physiotherapy Theory and Practice. 1994;10:153-9.

39. Griffin MO, Olney SJ, McBride I. Role of symmetry in gait performance of stroke subjects with hemiplegia. Gait Posture. 1995;3:132-42.

40. Van Peppen RP, Kwakkel G, Wood-Dauphinee S, Hendriks HJ, Van der Wees PJ, Dekker J. The impact of physical therapy on functional outcomes after stroke: what's the evidence? Clin Rehabil. 2004;18(8):833-62.

41. Teixeira-Salmela L, Lima R, Lima L, Morais S, Goulart F. Asymetry and functional performance in chronic stroke survivours before and after a training program in fitness center. Brazilian J Phys Ther. 2005;9(2):227-233.

42. Flansbjer U, Downham D, Lexell J. Knee muscle strength, gait performance, and perceived participation after stroke. Arch Phys Med Rehabil. 2006;87(7):974-80.

43. Bohannon R. Reference values for the five-repetition sit-to-stand test: a descriptive meta-analysis of data from elders. Percept Mot Skills. 2006;103(1):215-22.

Received: 01/26/2009

Recebido: 26/01/2009

Approved: 10/02/2009

Aprovado: 02/10/2009 